\title{
GGAAAT motifs play a major role in transcriptional activity of the human insulin gene in a pancreatic islet beta-cell line MIN6
}

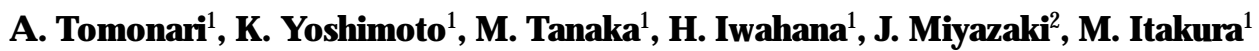 \\ ${ }^{1} O$ tsuka D epartment of Clinical and M olecular N utrition, School of M edicine, The U niversity of Tokushima, Tokushima, Japan \\ ${ }^{2}$ D epartment of M olecular E mbryology, I nstitute of D evelopment, A ging and Cancer, Tohoku U niversity, Sendai, J apan
}

Summary The insulin gene is specifically expressed in pancreatic islet beta cells. Various cis-acting D N A elements in the 5 '-flanking region of the human insulin gene were examined for their contribution to the transcriptional activity using sensitive human growth hormone (hGH) reporter plasmids. The hG H constructs, having successively deleted human insulin promoter sequences, were transfected to a pancreatic islet beta-cell line MIN6. The deletion of two GGAAAT (GG) motifs, GG2 at -145 to $-140 \mathrm{bp}$ and $\mathrm{G} \mathrm{G} 1$ at -134 to $-129 \mathrm{bp}$, decreased the transcriptional activity to $6.5 \%$ of that of the promoter sequence from -156 to $+1 \mathrm{bp}$. The selective mutations in both $\mathrm{G} G$ motifs also decreased the transcriptional activity to $5.5 \%$. One-base mutations of $G G 2$ and G G 1 decreased the transcriptional activity to 82 and $11 \%$, respectively. The two-base mutations between GG2 and $G G 1$ affected the transcriptional activity more strongly than those just outside the $G G$ motifs. A single set of $G G$ motifs in the upstream of thymidine kinase promoter increased the transcriptional activity to $216 \%$ compared to that of thymidine kinase promoter alone in M IN 6 cells. With an electrophoretic mobility shift assay (EM SA ), a nuclear factor in MIN 6 cells was shown to bind the DNA fragments containing two G G motifs. This factor did not bind to another G GA A A T-like sequence at -313 to $-305 \mathrm{bp}$ in the human insulin gene. These results suggested that the $G \mathrm{G}$ motifs contributed to the cell-specific transcription of the human insulin gene in association with the binding of the sequence-specific nuclear factor. [D iabetologia (1996) 39: 1462-1468]

Keywords Insulin gene, G G motif, transcription, pancreatic islet, M IN 6.
The insulin gene is specifically expressed in pancreatic islet beta cells. The role of cis-acting DNA elements involved in transcriptional regulation in islet beta cells has been more extensively studied for rat

R eceived: 27 M arch 1996 and in revised form: 10 J une 1996

Corresponding author: Professor M. Itakura, O tsuka D epartment of Clinical and M olecular Nutrition, School of M edicine, The U niversity of Tokushima, 3-18-15, Kuramoto-cho, Tokushima-city, 770 Japan

A bbreviations: hG H, human growth hormone; TK, thymidine kinase; SE A P, secreted-type of human placental alkaline phosphatase; RLU, relative light units; bp, base pair; EMSA, electrophoretic mobility shift assay; CAT, chloramphenicol acetyl-transferase; PCR, polymerase chain reaction; CMV, cytomegalovirus; FBS, fetal bovine serum. insulin I and II genes than the human insulin gene. Several transcriptional regulatory elements are located in the 5 '-flanking region within 350 base pairs (bp) from the transcriptional start site of the insulin gene [1-4]. Two kinds of elements, TA A T motifs and $\mathrm{E}$-box elements in the rat insulin I gene are known to play a crucial role in cell-specific transcriptional regulation. The TA A T motifs are located in A 4/A 3 at -215 to $-200 \mathrm{bp}$ and in $\mathrm{A} 1$ at -82 to $-72 \mathrm{bp}$ according to a simplified nomenclature for the cis-acting DNA elements in the insulin gene [5]. These elements were previously designated as the FLA T and P1 element, respectively. Insulin promoter factor 1 which is a homeodomain-containing protein, binds to these elements [6-8]. The E-box elements, E 2 at -239 to -232 bp and $E 1$ at -111 to -104 bp, previously designated as Far and Nir, respectively, contain the 
Table 1. Nucleotide sequences of double-stranded probes and competitors

\begin{tabular}{|c|c|c|c|}
\hline Name & $5^{\prime}$ end & Nucleotide sequence & $3^{\prime}$ end \\
\hline $\begin{array}{l}-156 / G G \\
-148 / G G\end{array}$ & $\begin{array}{l}-156 \\
-148\end{array}$ & $\begin{array}{c}\text { CCCA GCA CCA GGGAAATGGTCCGGAAATTGCA GCC } \\
\text { CA G G GAAATGGTCCG GAAATTGC }\end{array}$ & $\begin{array}{l}-122 \\
-126\end{array}$ \\
\hline $\begin{array}{l}-325 / \text { core } \\
-316 / \text { core }\end{array}$ & $\begin{array}{l}-325 \\
-316\end{array}$ & $\begin{array}{c}\text { A GCTTGGTCTA A TGTGGAAAGTGGCCCAGG } \\
\text { A A T GTGGAAGTGGCC }\end{array}$ & $\begin{array}{l}-297 \\
-301\end{array}$ \\
\hline
\end{tabular}

The number represents the nucleotide position from the transcriptional start site of the human insulin gene. Bold-faced letters denote the position of the $G \mathrm{G} 2$ and $\mathrm{GG} 1$. Underlined letters denote the position of the core enhancer sequence at - 313 to $305 \mathrm{bp}$

consensus sequence of G CCA TCTG with underlined letters showing consensus, to which nuclear factors containing basic helix-loop-helix structures bind [9]. A 4/A 3 and/or $E 2$ in the rat inulin I gene [10, 11], and $\mathrm{C} 1$, previously called as R IPE $3 \mathrm{~b} 1$, at -115 to $-107 \mathrm{bp}$ in the rat insulin II gene [12] were reported to play an important role in the glucose-responsive transcription.

The human insulin gene has three TA A T motifs of $A 5, A 3$, and $A 1$, which were previously called CT motifs of CT3, CT2, and CT 1, respectively (Fig.1). A 3 was reported to play a major role in the cell-specific and glucose-responsive transcription using chloramphenicol acetyl-transferase (CAT) expression assays in isolated rat islet cells [8]. To further understand the role of cis-acting D N A elements of the human insulin gene in transcriptional activity, we carried out a sensitive transient expression assay with human growth hormone ( $\mathrm{hGH}$ ) reporter plasmids transfected to a murine islet beta-cell line MIN6. M I 6 cells secrete insulin in response to glucose concentrations in its physiologic range [13], and glucose metabolism in MIN 6 cells including glucose transport, phosphorylation, and utilization was similar to that in isolated islets [14]. Due to these characteristics, M IN 6 cells serve as a useful substitute for isolated islets to study both cell-specific and glucose-responsive insulin biosynthesis. In addition to E 2 and A 3, we investigated the role of other cis-acting D N A elements located in their downstream, including $C 1$, $E 1$, and $A 1$, previously called RIPE $3 b 1, I E B 1$, and CT 1, respectively, and GGAAAT (GG) motifs in the present study.

\section{Materials and methods}

Plasmid constructs. The $\mathrm{hG} \mathrm{H}$ reporter plasmids having various sizes of deleted 5 '-flanking sequences of the human insulin gene, as shown in Figure 1, were constructed as follows. The fragments from $-341,-248,-230,-208,-187,-156,-128,-117$, -84 , and -74 to +1 bp of the transcriptional start site of the human insulin gene were amplified by polymerase chain reaction (PCR) using a plasmid, pgH I 12.5 [15] as a template, and inserted into the upstream of the promoterless $\mathrm{hGH}$ expression plasmid, pOGH (Nichols, San Juan Capistrano, Calif., USA) [16]. The PCR -amplified DNA sequences were confirmed by the dideoxy termination method. The hG H reporter plasmid driven by the herpes simplex virus thymidine kinase (TK) promoter was constructed by inserting the $\mathrm{TK}$ promoter of pB LCA T 2 [17] into a H indl II and BamH I site of pOG H, which was designated as PTK OG H. The double-stranded oligonucleotide including both $\mathrm{G} \mathrm{G}$ and $\mathrm{G} \mathrm{G} 1$ motifs was produced by annealing synthesized complementary oligonucleotides from 148 to $-126 \mathrm{bp}$, and it was inserted in the upstream of the TK promoter in PTK $0 \mathrm{GH}$, which was designated as PG G TK OG H. A plasmid containing a secreted-type of human placental alkaline phosphatase (SEAP) gene driven by a cytomegalovirus promoter, CM V-SEA P (Tropix, B edford, M ass., U SA ) [18], was used as an internal control. Plasmids prepared on a large scale were purified using column chromatography (Qiagen, Chatsworth, Calif., U SA ) according to the manufacturer's instructions. B ecause the amount of plasmids necessary for detection and the portion of the sample necessary for assay are both significantly smaller in the $\mathrm{hG} \mathrm{H}$ reporter system than the CA T assay system, the sensitivity of $\mathrm{hG} \mathrm{H}$ reporter plasmids is at least 10 times more sensitive than that of the CA T plasmids [16].

Cell culture and DNA transfection. M IN 6 cells were grown in Dulbecco's modified Eagle medium equilibrated with $5 \%$ $\mathrm{CO}_{2}$ and $95 \%$ air at $37^{\circ} \mathrm{C}$. The medium was supplemented with $15 \%$ fetal bovine serum (FBS), $50 \mu \mathrm{g} / \mathrm{ml}$ streptomycin, and 50 units/ml penicillin. M I 6 cells used in this study were harvested at passages of 20-23. The reporter constructs were transfected to the cells by a cationic liposome-mediated method. $5 \times 10^{6}$ cells were plated on a $90-\mathrm{mm}$ dish, then $5 \mu \mathrm{g}$ of the test plasmid and $2 \mu \mathrm{g}$ of CMV-SEAP plasmid were mixed with Lipofectin (GIBCO/BRL, G aithersburg, Md., USA) and added to the medium at $26.3 \mathrm{mmol} / \mathrm{l}$ glucose. NIH/3T 3 cells, which were obtained from Japanese Cancer $R$ esearch $R \mathrm{e}$ sources Bank, Tokyo, Japan, were cultured under the same condition as M IN 6 cells, except that the culture medium contained $10 \% \mathrm{FBS}$ and $6.8 \mathrm{mmol} / / \mathrm{l}$ glucose. The culture medium for the $\mathrm{hGH}$ and SEA P assay was sampled $48 \mathrm{~h}$ later. The differences of the transfection efficiency among the experiments were corrected by the SE A P activity.

A ssay of secreted hG H or SE A P. The amount of secreted hG H in the culture medium was assayed using an immunoradiometric assay kit ( $D$ aiichi R adioisotope L aboratory, Tokyo, Japan). The activity of secreted SEA P in the culture medium was assayed using a chemiluminescence assay kit, Phospha-Light (Tropix, B edford, M ass., U SA ) [19] and the transcriptional activity was standardized for 10000 relative light units (RLU) of SE A P activity.

E lectrophoretic mobility shift assay (E M SA). Nuclear extracts were prepared from M IN 6, NIH/3T 3, and COS-7 cells by the technique of A ndrews et al. [20]. Synthesized oligonucleotides listed in Table 1 were annealed with synthesized complementary strands to make double stranded probes and competitors. Probes were end-labelled with $\left[\alpha-{ }^{32} \mathrm{P}\right] \mathrm{BCTP}(3000 \mathrm{Ci} / \mathrm{mmol}$, $10 \mathrm{mCi} / \mathrm{ml}$ )(A mersham, A mersham, Bucks., UK) using the K lenow fragment of DNA polymerase I. Binding reactions 


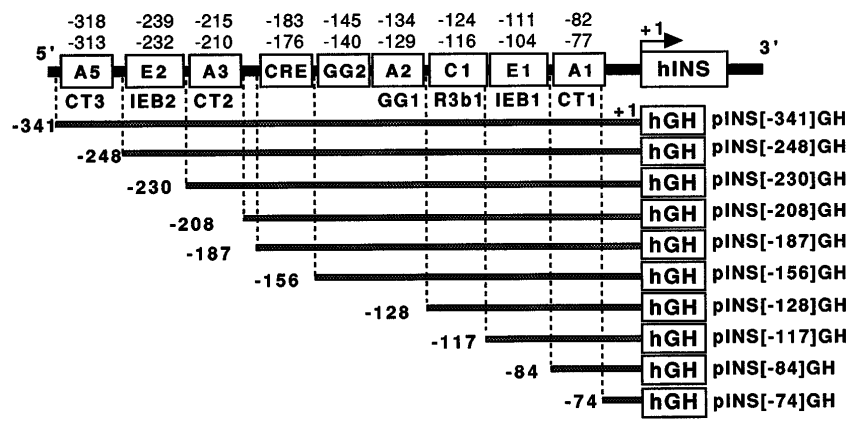

Fig. 1. The constructs of hG $\mathrm{H}$ reporter plasmids having successively deleted fragments of the human insulin promoter. The number in the figure represents the nucleotide position from the transcriptional start site of the human insulin gene. The upper panel shows the relative location of the cis-acting D NA elements and their nucleotide position. The names according to the simplified nomenclature are shown in boxes except G G2, with their previous names shown below

A

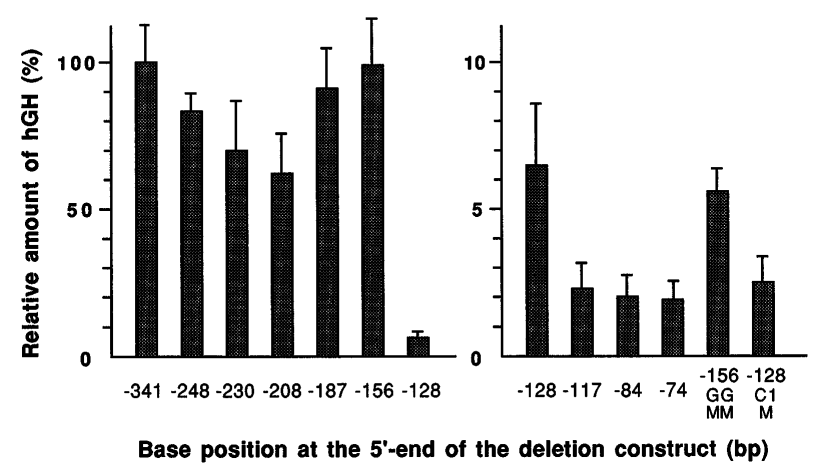

Fig. 2. Transcriptional activity of the human insulin promoter in a series of successive deletion constructs in MIN 6 cells. M I 6 cells were transfected with $5 \mu \mathrm{g}$ of the indicated deletion construct and $2 \mu \mathrm{g}$ of a control plasmid, CM V-SEA P. These cells were grown for $48 \mathrm{~h}$ in the culture medium with $26.3 \mathrm{mmol} / \mathrm{l}$ glucose containing $15 \% \mathrm{FBS}$. The amount of secreted hGH and the activity of SEAP in the culture medium were measured. The promoter activity of various deleted fragments of the human insulin gene was standardized by the relative amount of hGH to $10000 \mathrm{RLU}$ of SEA P activity. The results are presented as a percentage of the amount of secreted $\mathrm{hGH}$ from pINS[-341]GH. The number in the figure represents the nucleotide position from the transcriptional start site of the human insulin gene. E ach bar represents mean \pm SD of four independent transfections

contained $25 \mathrm{mmol} / \mathrm{l}$ 4-(2-hydroxyethyl)-1-perazine ethanesulfonic acid (pH 7.8), $60 \mathrm{mmol} / / \mathrm{K} \mathrm{Cl}, 5 \mathrm{mmol} / / \mathrm{M} \mathrm{gCl}, 2 \mathrm{mmol} / \mathrm{l}$ dithiothreitol, $10000 \mathrm{dpm}$ of end-labelled double-stranded oligonucleotides, $5 \mu \mathrm{g}$ nuclear extract, and $2 \mu \mathrm{g}$ poly $(\mathrm{dl}-\mathrm{dC}) /$ poly(dl-dC) (Pharmacia, U ppsala, Sweden). A fter the binding reaction, samples were loaded onto a $5 \%$ non-denaturing polyacrylamide gel and run in high ionic strength buffer. A fter electrophoresis, the gels were dried and subjected to autoradiography.

Statistical analysis. Statistical analysis was performed by Student's unpaired t-test. A value of $p$ less than 0.05 was considered statistically significant.
Results

Transcriptional activity of the human insulin promoter in a series of successive deletion constructs. The transcriptional activity of the successively deleted human insulin promoter (Fig. 1) was estimated with the amount of $\mathrm{hG} \mathrm{H}$ secreted for $48 \mathrm{~h}$ after transfection (Fig.2). In the same culture medium, the SE A P activity which was calculated from a standard curve obtained in each experiment, fell into a narrow range of $16 \%$ of standard deviation of the mean in each experiment, suggesting that the differences of transfection efficiency among these deletion constructs were relatively small. The amount of hG $\mathrm{H}$ from pINS[-341]GH, which was standardized for SE A P activity, was maximum among these deletion constructs. The removal of the fragment from -341 to $-249,-231$, or -209 bp gradually decreased the transcriptional activity to 83,70 , or $62 \%$ (Fig. $2 A$ ). In these regions, there are positive regulatory elements including A 5 at -318 to -313 bp, E 2 at -239 to $-232 \mathrm{bp}$, and $\mathrm{A} 3$ at -215 to $-210 \mathrm{bp}$. Further removal of the fragment from -208 to -188 , or -157 bp resumed the transcriptional activity to the same degree as that of pl NS[-341] G H .

The most drastic effect on the transcriptional activity was observed when the fragment from -156 to -129 bp was deleted (Fig. 2A). The amount of secreted hGH from plNS[-128]GH was $6.5 \%$ of that from pINS[-156]G H $(p<0.001 ; n=4)$. In this region, there are two GGAAAT sequences, designated as G $G$ motifs, including $G G 2$ at -145 to -140 bp and G G 1 at -134 to -129 bp [1]. A Ithough the $G \mathrm{G} 1$ was newly designated as $A 2$ by the simplified nomenclature, no new name was assigned to the $G G 2$. For this reason, we have used the terms of $G G$ motifs, $G G 1$, and $G G 2$ in this paper. To examine the effect of the removal of the sequences of the $G G$ motifs on the transcriptional activity, we made another hG $\mathrm{H}$ construct, pINS[-156GGMM]GH, in which the GGAAAT sequences of the $G G 2$ and the $G G 1$ were selectively mutated to $\underline{\mathrm{CTGCAG}}$ and CTCGAG, respectively, with underlined letters showing mutated bases in the fragment from - 156 to $+1 \mathrm{bp}$. The amount of secreted $\mathrm{hG} \mathrm{H}$ from this construct was only $5.5 \%$ of that from pINS[-156] G H in M IN 6 cells $(p<0.001 ; n=4)$ (Fig. 2B). In NIH/3T 3 cells, pINS[-156GGMM ]GH did not significantly change the transcriptional activity when compared to that of pINS[-156]G H (data not shown).

The transcriptional activity of the deleted fragments shorter than that of pI N S[-128] G H was further examined (Fig. 2B). The removal of the fragment from -128 to -118 bp significantly decreased the transcriptional activity from 6.5 to $2.2 \%$ of that from pINS[-156]GH $(p<0.02 ; n=4)$. A possible cis-acting D N A element located at -124 to $-116 \mathrm{bp}$ in this region corresponds to $\mathrm{C} 1$ in the rat insulin $\mathrm{II}$ gene [2, 
Table 2. N ucleotide sequences of the human insulin promoters in the indicated hG $\mathrm{H}$ constructs

\begin{tabular}{|c|c|c|}
\hline Name of hG H constructs & $5^{\prime}$ end & Nucleotide sequence \\
\hline $\begin{array}{l}\text { pINS[- 156]G H } \\
\text { pINS[- 156G G M M ]GH }\end{array}$ & $\begin{array}{l}-156 \\
-156\end{array}$ & $\begin{array}{l}\text { CCCA G CA CCA G G G A A A T G G TCC G G A A A TT GC } \\
\text { CCCA G CA CCA G CTCG A G G G TCC CT G CA GTG C }\end{array}$ \\
\hline $\begin{array}{l}\text { pl NS[- 156G G 2M ] G H } \\
\text { plN S[- 156G G 1M ]G H }\end{array}$ & $\begin{array}{l}-156 \\
-156\end{array}$ & $\begin{array}{l}\text { CCCA G CA CCA G G G A CA TG G TCC G G A A A TTG C } \\
\text { CCCA G CA C CA G G G A A A TG G TCCG G A CA TTG C }\end{array}$ \\
\hline $\begin{array}{l}\text { pI NS[- 156G G 2M 5']G M } \\
\text { pIN S[- 156G G 2M 3']G H } \\
\text { pI NS[- 156G G 1M 5']G H } \\
\text { pI NS[- 156G G 1M 3']G H }\end{array}$ & $\begin{array}{l}-156 \\
-156 \\
-156 \\
-156\end{array}$ & 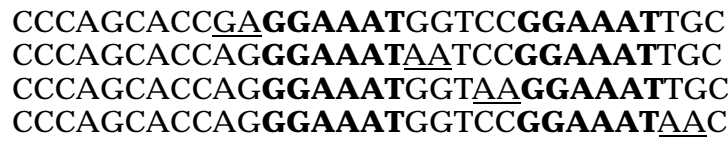 \\
\hline
\end{tabular}

Nucleotide sequences from the $5^{\prime}$ ends to -126 bp are shown. A ll constructs contain the same 3 ' sequence up to +1 bp. U nderlined letters denote the mutated sequences. B old-faced letters denote the position of the G G 2 at - 145 to - 140 bp and the G G 1 at - 134 to $-129 \mathrm{bp}$

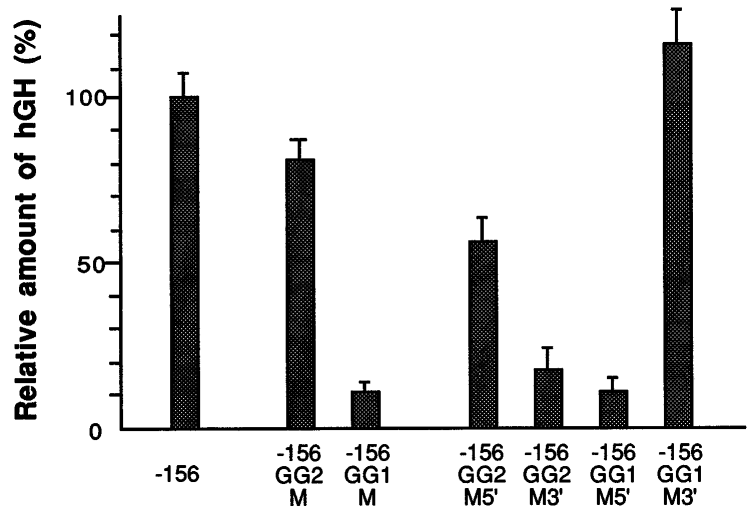

Fig. 3. E ffects of small mutations in and outside the $G \mathrm{G}$ motifs on transcriptional activity of the human insulin promoter in M IN 6 cells. The data presentation and statistical analysis are the same as in Figure 2 except that the results are presented as a percentage of the amount of hGH concentration for pINS[-156]GH. The names of the hGH constructs and their nucleotide sequences of the human insulin promoters are described in Table 2. E ach bar represents mean \pm SD of six independent transfections

12 , 22]. The activity of $\mathrm{C} 1$ of the rat insulin II gene was reported to be abolished by the substitution of two nucleotides of TC with CG [12, 22]. To examine the effect of this mutation in the human insulin gene on the transcriptional activity, we made another hGH construct, plNS[-128C 1M ]G H. pINS[-128 $\mathrm{C} 1 \mathrm{M}$ ]G H had the fragment from -128 to $+1 \mathrm{bp}$ in which $C 1$ sequence of GCCTCA GCC was mutated to G CCCGA G CC. The introduction of this mutation decreased the transcriptional activity from 6.5 to $2.5 \%(p<0.02 ; n=4)$ (Fig. 2B). Further deletions of the fragment from -117 to -85 and -75 bp which contained $\mathrm{E} 1$ at -111 to $-104 \mathrm{bp}$ and $\mathrm{A} 1$ at -82 to $-77 \mathrm{bp}$, respectively, gradually decreased the transcriptional activity to 2.0 and $1.9 \%$, respectively (Fig. $2 \mathrm{~B}$ ). The amount of secreted $\mathrm{hGH}$ from the promoterless pOGH, which was well above the detection limit of hG $\mathrm{H}$ at $10 \mathrm{pg} / \mathrm{ml}$ in our experimental system, was less than $0.8 \%$ of that from pINS[-341]GH and pINS[-156]G H (data not shown).
Small mutations in and outside the $G G$ motifs affected the transcriptional activity. The effects of onebase mutation from GGA $\underline{A} A T$ to $G G A \underline{C A} T$ in the $G G 2$ or the $G G 1$ were examined. The constructs of pIN S[-156G G 2M ] G H and pINS[-156G G 1M ] G H had the above-mentioned one-base substitutions in the $\mathrm{GG} 2$ and the $\mathrm{GG} 1$, respectively (Table 2 ). A Ithough both constructs significantly decreased the transcriptional activity $(p<0.001 ; n=6)$, pINS[-156 GGIM JGH decreased more strongly to $11 \%$ than that of $82 \%$ for pINS[-156G G 2M]GH (Fig.3), suggesting that the more important role of $G G 1$ than GG2. A s shown in Table 2, four hGH constructs with mutations of two bases in the 5 '- or 3 '-flanking regions of the $G G$ motifs were made, and the effects of these mutations on the transcriptional activity were examined. A s shown in Figure 3, pINS[-156 G G2M 5']G H , pINS[-156G G 2M 3']G H , pINS[-156 G G 1M 5']GH, and pINS[-156G G 1M 3']G H significantly changed the transcriptional activity to 56,17 , 10 , and $117 \%$, respectively $(p<0.001,<0.001$, $<0.001$, and $<0.01$, respectively; $n=6$ ). These results suggested that the sequences between the $G G 2$ and $G G 1$ were affected more strongly than those just outside the $G \mathrm{G}$ motifs in the transcriptional activity.

O ne set of GG motifs enhanced the transcriptional activity of the TK promoter in M IN 6 cells. To examine the effect of one set of $G G$ motifs on the transcriptional activity in MIN 6 or NIH/3T 3 cells, the transcriptional activities of the $\mathrm{PTKOGH}$ and pG GTK OGH were examined (Fig.4). pG GTK OGH had the fragment from -148 to -126 bp of the human insulin gene including two GG motifs, but without the elements of $C 1, E 1$, or $A 1$, in the upstream of the TK promoter (Fig. 4A). pGGTKOGH increased the transcriptional activity to $216 \%$ compared to that of pTKOGH in MIN6 cells $(p<0.001 ; n=6)$ (Fig.4B, left). In NIH/3T3 cells, however, pGGTKOGH did not significantly change the transcriptional activity compared to that of PTKOGH (Fig. 4B, right). 
A. Constructs

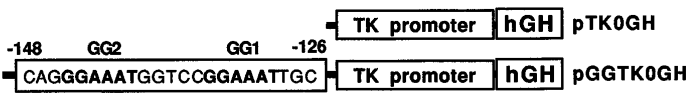

B. Transcriptional Activity
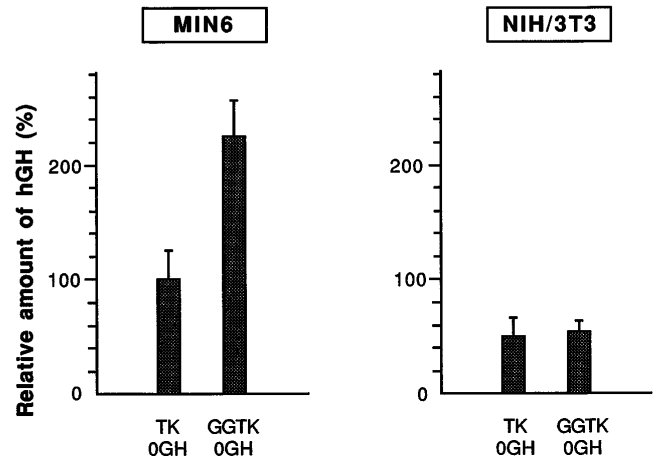

Fig. 4. A , B Effects of the isolated $G \mathrm{G}$ motifs on the transcriptional activity of the TK promoter in M IN 6 and NIH /3T 3 cells. A The hG H constructs with or without the $\mathrm{G} G$ motifs in the upstream of the TK promoter. B old-faced letters in the nucleotide sequences denote the consensus sequence of the two G G motifs. B The transcriptional activities of these constructs in M IN 6 and NIH/3T 3 cells are shown. The data presentation and statistical analysis are the same as in Figure 2 except that the results are presented as a percentage of the amount of hG H concentration for pTK OG H in M IN 6 cells. E ach bar represents mean $\pm S D$ of six independent transfections

Binding of a nuclear factor to the D N A fragment containing both the $G \mathrm{G} 2$ and the $G \mathrm{G} 1$. Trans-acting factors to the $G G$ motifs in the human insulin gene were studied using EMSA. A s shown in Figure $5 \mathrm{~A}$, the EMSA, using the labelled oligonucleotide of $-156 / G$ G containing the sequences from -156 to -122 bp as a probe (Table 1) and the nuclear extract from MIN 6 cells, showed a single retarded band of the D N A -protein complex. This signal of the D NA -protein complex disappeared by adding the excess of non-labelled oligonucleotide of -148/G G from - 148 to -126 bp as a competitor (Fig. 5A ). The opposite experiment using the labelled $-148 / G \mathrm{G}$ as a probe also formed a single retarded band (Fig. 5B) which disappeared by the excess of non-labelled $-148 / G \mathrm{G}$ in lane 2 and also -156/G G (data not shown), indicating that the common oligonucleotides containing the two G G motifs are responsible for their binding activity to the nuclear factor in M IN 6 cells. There is another GGAAAT-like motif in the human insulin gene, which was G T G G A A A G T at -313 to -305 bp designated as a core enhancer sequence [1]. A s shown in Figure $5 B$, the excess of oligonucleotides of $-325 /$ core from -325 to $-297 \mathrm{bp}$ and $-316 /$ core from -316 to -301 bp (Table 1) did not compete with the G G binding activity of the labelled $-148 / G \mathrm{G}$. These results showed that the $\mathrm{G} G$-binding factor did not bind to the core enhancer sequence of the human insulin
A

probe : $-156 / G G$

B

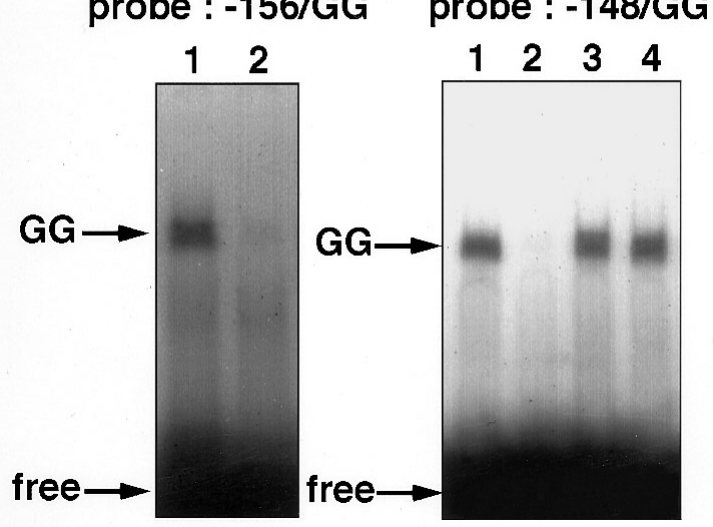

Fig.5. Binding of the oligonucleotides containing the $G G 2$ and the G G 1 to the nuclear extract from M IN 6 cells. The binding specificity of nuclear protein to probes and competitors (Table 1) was tested by the E M SA. N uclear extracts were added to the ${ }^{32} \mathrm{P}$-labelled probes and the DNA -protein complexes were analysed on a $5 \%$ non-denaturing polyacrylamide gel in high ionic strength buffer. The binding specificity was examined by adding a 50 -fold excess of the non-labelled oligonucleotides as competitors. $L$ anes 1 and 2 in panel $\mathbf{A}$ denote no competitor and a competitor of $-148 / G \mathrm{G}$, respectively. $L$ anes 1 through 4 in panel B denote no competitor, a competitor of $-148 / G$ G, $-325 /$ core, and -316/core, respectively. The upper and lower arrows show the specific G G-binding activity and the non-specific reaction plus the labelled free probe, respectively

gene, and suggested that nuclear factors bind to the G G motifs in a sequence-specific manner.

The G G -binding factor in M IN 6 cells was not present in NIH/3T 3 cells. Tissue distribution of this G G -binding factor was examined. A s shown in Figure 6, similar G G -binding activity was observed weakly in the nuclear extract from NIH/3T 3 cells using labelled $-148 / G \mathrm{G}$ as a probe. In spite of the apparent similarity, this binding activity was competed with the excess of the non-labelled oligonucleotide sequence including not only -148/G G, but also -325/core and -316/ core. These results showed that the $\mathrm{G} G$-binding factor in M IN 6 was different from that in NIH /3T 3. The same property of the $\mathrm{GG}$-binding as observed in the extract from NIH/3T 3 cells was also recognized in the extract from COS-7 cells with the EMSA (data not shown). These results suggested that the GG binding factor observed in M IN 6 cells was specific to this cell line and may also be specific to pancreatic islet beta cells.

\section{Discussion}

Various cis-acting D N A elements of the human insulin gene were examined for their contribution to the transcriptional activity. The constructs having the 
probe : $-148 / G G$

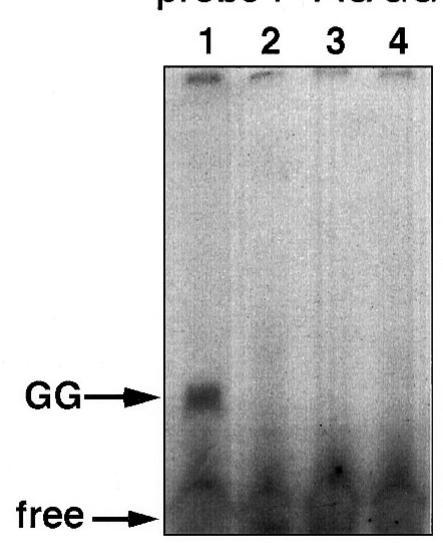

Fig. 6. Binding of the oligonucleotides containing the $\mathrm{GG} 2$ and the G G 1 to the nuclear extracts from NIH/3T 3 cells. The data presentation is the same as in Figure 5. L anes 1 through 4 denote no competitor, a competitor of $-148 / G$ G, $-325 /$ core, and $-316 /$ core, respectively. The upper and lower arrows show the specific $\mathrm{G} G$-binding activity and the non-specific reaction plus the labelled free probe, respectively

deleted human insulin promoter, as shown in Figure $2 \mathrm{~A}$, showed mild changes in the transcriptional activity ranging from 62 to $100 \%$ among deletion constructs from -341 to $-156 \mathrm{bp}$. B oam et al. [1] previously showed that the existence of the negative regulatory element called NRE at -279 to $-258 \mathrm{bp}$ resulted in a 25 -fold reduction of the transcriptional activity in a hamster insulinoma cell line HIT, but we did not observe such strong negative effects on the overall transcriptional activity in M IN 6 cells. It is presumably due to the presence of the positive element located within the region from -341 to -279 bp as reported by Clark et al. [21].

The deletion of the sequence from -156 to $-129 \mathrm{bp}$ drastically decreased the transcriptional activity to about $6 \%$, which was not recovered by the further deletion constructs. These results suggested the presence of a strong cis-acting DNA element between -156 and $-128 \mathrm{bp}$. B ecause the selective mutations of two G G motifs in this region decreased the transcriptional activity in MIN 6 cells to about $6 \%$, the G G motifs were regarded to be mainly responsible for the transcriptional activity of the human insulin gene. O nly one-base mutation in G G 1 decreased the transcriptional activity to as low as $11 \%$ of that of pIN S[-156]G H, while one-base mutation in G G 2 decreased it to $82 \%$. A lthough these data suggested the more important role of GG 1 than G G 2 in the transcriptional activity, further study is necessary to fully elucidate the distinctive roles of the $G G$ motifs.

The removal of the fragment from -128 to $-118 b p$ and the introduction of mutation from TC to $C G$ in this region significantly decreased the transcriptional activity from 6.5 to 2.2 and $2.5 \%$ of that of pINS [-156] GH, respectively, which corresponded to 34 and $38 \%$ of that of pIN S[-128]G H, respectively. This region contains the sequence corresponding to $\mathrm{C} 1$ in the rat insulin II gene. These results suggested that $\mathrm{C} 1$ in the human insulin gene played a role in the transcriptional activity.

The effects of the introduced isolated G G motifs on the beta-cell-specific transcriptional activity were examined using the hG $\mathrm{H}$ construct having the fragment from -148 to $-126 \mathrm{bp}$ in the upstream of the TK promoter (Fig.4). Introduction of the isolated GG motifs resulting in pGGTKOGH increased the transcriptional activity in MIN 6 cells to $216 \%$ compared to that of the TK promoter alone in PTK OG H. In NIH/3T 3 cells, the introduction of the isolated G G motifs did not significantly change the transcriptional activity, suggesting that the $G \mathrm{G}$ motifs function in a beta-cell-specific manner.

E M SA showed the presence of a nuclear factor in M IN 6 cells that bound to the D NA fragment containing the $G G$ motifs in a sequence-specific manner. This nuclear factor was not present in $\mathrm{NIH} / 3 \mathrm{~T} 3$ or COS-7 cells, suggesting that this factor is specific to pancreatic islet beta cells. Further characterization of this factor regarding the distinctive roles of the G G 2 and the $G G 1$ in its binding is underway in our laboratory.

The $G G$ motifs in the human insulin gene were first designated by Boam et al. [1]. They found that the region between -153 and -127 bp containing two GGAAAT sequences was protected by a nuclear protein of a pancreatic beta-cell line of HIT M 2.2.2 or HIT.T 15-G using the D N ase footprint analysis. In addition, they showed that the ubiquitous factor bound to the $G \mathrm{G} 1$, and that the islet beta cell-specific factor bound to the GG2. However, the functional role of the GG motifs was not studied. Shieh et al. [22] showed that the region between -127 and -89 bp of the rat insulin II gene played an important role in the islet beta cell-specific transcription. This region was designated as RIPE 3, which contains $G \mathrm{G} 1, \mathrm{C} 1$, and $E 1$. $A$ lthough the roles of $C 1$ and $E 1$ in the rat insulin II gene were examined, the role of the G G I has not been further evaluated.

In this study, the $G G$ motifs in the human insulin promoter were shown to significantly contribute to the transcriptional activity in a murine islet beta-cell line of MIN6. Furthermore, the new nuclear factor was shown to specifically bind to the $G \mathrm{G}$ motifs by the EMSA for the first time. These data suggested that the $G G$ motifs contributed to the transcriptional regulation of the human insulin gene by mediating the binding of the specific nuclear factor. Further study on the characteristics of this nuclear factor, including its molecular cloning, and elucidation of the controlling mechanism of the function of this factor is necessary to understand the whole mechanisms of the transcriptional regulation of the human insulin gene. 
A cknowledgements. We thank Professor G.I. Bell, at Howard $\mathrm{H}$ ughes Medical Institute, U niversity of Chicago for the human insulin gene plasmid, pgH I 12.5, and D r. G. Schütz at Institut für Zell- und Tumor-Biologie, Deutsches Krebsforschungszentrum for the TK promoter-contained in a CA T plasmid of pBLCA T2. We also appreciate the technical assistance by $Y$. Suganaka, K. Nakajima, and M Y asuda. This work was supported in part by a $\mathrm{G}$ rant from $\mathrm{O}$ tsuka Pharmaceutical Factory Inc. for $\mathrm{O}$ tsuka D epartment of Clinical and M olecular Nutrition, School of M edicine, The U niversity of Tokushima.

\section{References}

1. Boam DSW, Clark A R, Docherty K (1990) Positive and negative regulation of the insulin gene by multiple transacting factors. J Biol Chem 265: 8285-8296

2. Whelan J, Poon D, Weil PA, Stein R (1989) Pancreatic $\beta$ cell-type-specific expression of the rat insulin II gene is controlled by positive and negative cellular transcriptional elements. M ol Cell Biol 9: 3253-3259

3. Karlsson O, Edlund T, Moss J B, R utter WJ, Walker M D (1987) A mutational analysis of the insulin gene transcription control region: Expression in beta cells is dependent on two related sequences within the enhancer. Proc $\mathrm{N}$ atl A cad Sci U SA 84: 8819-8823

4. G erman M S, M oss L G, Wang J, R utter WJ (1992) The insulin and islet amyloid polypeptide genes contain similar cellspecific promoter elements that bind identical $\beta$-cell nuclear complexes. M ol Cell Biol 12: 1777-1788

5. German M , A shcroft S, D ocherty K et al. (1995) The insulin gene promoter. A simplified nomenclature. Diabetes 44: $1002-1004$

6. O hlsson H, K arlsson K, E dlund T (1993) IPF 1, a homeodomain-containing transactivator of the insulin gene. E M BO J 12: 4251-4259

7. M acFarlane W M, R ead M L, G illigan M, Bujalska I, D ocherty K (1994) G lucose modulates the binding activity of the $\beta$-cell transcription factor IU F 1 in a phosphorylationdependent manner. Biochem J 303: 625-631

8. Petersen HV, Serup P, L eonard J, M ichelsen BK, M adsen OD (1994)Transcriptional regulation of the human insulin gene is dependent on the homeodomain protein STF1/ IPF 1 acting through the CT boxes. Proc Natl A cad Sci USA 91: 10465-10469

9. Nelson C, Shen L, M eister A, Fodor E, R utter WJ (1990) Pan: a transcriptional regulator that binds chymotrypsin, insulin, and A P-4 enhancer motifs. G ene D ev 4: 1035-1043
10. M elloul D, B en-Neriah Y, Cerasi E (1993) G lucose modulates the binding of an islet-specific factor to a conserved sequence within the rat I and the human insulin promoters. Proc N atl A cad Sci U SA 90: 3865-3869

11. G erman M S, Wang J (1994) The insulin gene contains multiple transcriptional elements that respond to glucose. $\mathrm{M}$ ol Cell Biol 14: 4067-4075

12. Sharma A , Stein R (1994) G lucose-induced transcription of the insulin gene is mediated by factors required for $\beta$-celltype-specific expression. M ol Cell B iol 14: 871-879

13. M iyazaki J -I, A raki K, Y amato E et al. (1990) Establishment of a pancreatic $\beta$ cell line that retains glucose-inducible insulin secretion: Special reference to expression of glucose transporter isoforms. Endocrinology 127: 126-132

14. Ishihara H, A sano T, Tsukuda K et al. (1993) Pancreatic beta-cell line M IN 6 exhibits characteristics of glucose metabolism and glucose-stimulated insulin secretion similar to those of normal islets. D iabetologia 36: 1139-1149

15. B ell G I, Pictet R, R utter WJ, Cordell B, Tischer E , G oodman H M (1980) Sequence of the human insulin gene. $\mathrm{Na}$ ture 284: 26-32

16. Selden R F, H owie K B, R owe ME , Goodman H M, M oore DD (1986) H uman growth hormone as a reporter gene in regulation studies employing transient gene expression. Mol Cell Biol 6: 3173-3179

17. L uckow B, Schütz G (1987) CA T constructions with multiple unique restriction sites for the functional analysis of eukaryotic promoters and regulatory elements. Nucleic A cids R es 15: 5490

18. B erger J, H auber J, H auber R, G eiger R, Cullen B R (1988) Secreted placental alkaline phosphatase: A powerful new quantitative indicator of gene expression in eukaryotic cells. G ene 66: 1-10

19. B ronstein I, Fortin J J, Voyta J C et al. (1994) Chemiluminescent reporter gene assays: sensitive detection of the GU S and SE A P gene products. B ioTechniques 17: 172-177

20. A ndrew NC, Faller DV (1991) A rapid micropreparation technique for extraction of DNA -binding proteins from limiting numbers of mammalian cells. Nucleic A cids Res 19: 2499

21. Clark A R, Wilson ME, Leibiger I, Scott V, Docherty K (1995) A silencer and an adjacent positive element interact to modulate the activity of the human insulin promoter. E ur J B iochem 232: 627-632

22. Shieh S-Y, T sai M -J (1991) Cell-specific and ubiquitous factors are responsible for the enhancer activity of the rat insulin II gene. J Biol Chem 266: 16708-16714 